\title{
THE MULTIFUNCTIONALITY AND SUSTAINABILITY OF SMALL AND MEDIUM ENTERPRISES IN TOURISM-BASED RURAL COMMUNITIES
}

\author{
Oleg PETELCA ${ }^{1}$, Ciprian-Constantin PĂTRĂUCEANU², lurie BEȘLIU ${ }^{3}$ \\ ${ }^{1}$ Alexandru loan Cuza University of lași, România \\ 2University of Oradea, România \\ ${ }^{3}$ Alecu Russo State University of Bălți, Republic of Moldova \\ oleg.petelca@gmail.com \\ patrauceanuc@yahoo.com \\ iurie.besliu@gmail.com
}

\begin{abstract}
The economic impact of tourist activity depends largely on the character of the area or space where it is practised (e.g., developed, developing or less developed). It also depends on the administration or, in broader terms, management of this complex activity and finality through consumption. The latter is related to both customer satisfaction and the satisfaction of the travel agency providing services, to the degradation of certain traditions and the disturbance of the economic, social, cultural, demographic and environmental balance in local communities. The globalisation process and the technological evolution determine visible and behavioural changes because competitiveness is related to technological efficiency. Tourism can generate substantial income, thus contributing to regional development and dynamizing the labour market and companies activating in that sector. By allocating various funds, we can improve the quality of services and renovate accommodation facilities, which enhances the popularity of the location and increases income, implicitly. This paper approaches rural tourism and entrepreneurship within a microeconomic approach. It is motivated by the fact that the most common tourist activities are small and medium enterprises, which are not always sustainable enough businesses. Hence, awakening the entrepreneurial spirit is one of the most notable challenges for the actors involved in small and medium enterprise development in rural areas. This paper highlights the role and challenges of small and medium enterprises activating in the tourism field in rural areas. In addition, the paper proposes a way for overcoming the constraints and difficulties imposed by rural communities, based on the connection between the traditional rural community and a human network existing outside the traditional territorial community. This network extending beyond the traditional territorial border may be complementary to the rural community. In this context, strategic cooperation becomes relevant; it is the solution for overcoming the challenges faced by other industries, too. Furthermore, rural tourism allows producers to mobilise (on a wider scale) the local resources redeemed within the mono-farm activities. Thus, they may attain the goal of using and preserving their rural heritage.
\end{abstract}

Key words: rural tourism; development; rural area: recreation; entrepreneurship; small and medium enterprises

JEL classification: L83; Q26; Z32 


\section{Introduction}

The phrase "rural tourism" has a broad connotation: it indicates tourist activity, in general, unfolded in rural areas, as well as tourist activities carried out by agricultural producers. Agritourism defines the tourist activity of agricultural producers, while rural tourism is often used concerning agritourism. In this respect, rural tourism acquires various interpretations. An increasing number of researchers from developing countries are working on community-based rural homestays, especially in the Asia Pacific region (Janjua et al, 2021). In this paper, rural tourism includes the agritourism practised by agricultural producers and community-based activities (i.e., tourist activity carried out by rural residents or by a group of rural residents, not necessarily in the agricultural field, but in tourist activities related to agriculture). This paper brings a contribution to theoretical and empirical research on rural tourism from a microeconomic perspective.

While research in the community tourism field has extended gradually to doublefolded topics (environmental and social), they have accounted for most studies, while the economic aspects have not represented a focusing point. It is one of the reasons why entrepreneurship in the tourism-based rural areas often face sustainability challenges at the end of the public or international support projects. One should investigate entrepreneurship in rural tourism extensively to improve this situation through both quantitative and qualitative approaches. It is one of the most common issues in every rural area, in developing and developed economies alike.

The purpose of this study is to determine the benefits of rural tourism, to find out to what extent rural communities use the benefits of rural tourism and to find solutions to use the benefits of rural tourism for the sustainable development of rural communities.

\section{Methodology}

In the study, the deductive logical approach was used. It was based on the elaboration of judgments that anchored on independent statements considered correct and not contradictory. The technique of abstraction has been used in order to bring the concrete elements to their general essentials and to highlight the most general aspects in the form of concepts. The articles studied were selected from the Web of Science database. Articles were searched for by the words "sustainability of rural tourism". After reading the name, the relevant articles were selected. Selected articles and materials from bibliographic lists that were accessed were studied.

\section{Tourism-based rural communities}

Within tourism-based rural communities, entrepreneurship is thought to encompass the activities carried out by operators introducing innovations in their products. It would also include innovations in production processes and the organisation of local resource management. Ultimately, it would comprise the creation of supply. Consequently, the purpose of tourism-based rural communities is to make a change and create demand for the products manufactured by the community through the collective efforts of communities. The decisive force for rural 
transformation is the transition to a post-productive society, which in rural areas, is characterized, among other things, by the reorientation of the economics from agriculture to tourism. The rural landscape is becoming an agricultural production area into a consumption area for tourism and housing (Epuran, 2021).

\subsection{Development of multifunctionality through rural tourism}

Multifunctionality entails positive effects, and it is defined as a common product generated by agricultural production and creating benefits. Multifunctionality involves a new social role for agriculture. However, it does not mean that multifunctionality automatically generates a new income source for agricultural producers. Multifunctionality has been defined as general positive effects created due to the technical combination between tourist activity and agriculture products. It means that it is impossible to make a technical distinction from the agricultural production process. In an agrarian community, the community functions, namely the share capital of the community or the community capital (Zahra \& McGehee, 2013; Knollenberg, Brune, Harrison, \& Savage, 2021), ensuring the survival of the members, is crucial for generating multifunctionality. This function is the prerequisite of rural community tourism. In this respect, multifunctionality is also a consequence of the institutional community of communitarian function. Multifunctionality is not internalised, and it does not generate income opportunities automatically. Consequently, efforts are necessary to attract incomes for the parties interested in the progress of rural communities focusing on tourist activities.

\subsection{Community tourism}

A community-based approach has been widely used in developing economies to overcome various social and economic challenges. Walzer (2009) has focused on small enterprise and entrepreneurship issues for practicians in the context of local economic development. Robinson and Green (2011) have also tried to mitigate the gap between theory and practice within their case studies. Fink et al. (2013) have used case studies focusing on rural small enterprises from the perspective of community entrepreneurship concerning Central Europe. Haughton (2013) has collected case studies on the economic development of communities, notably in the United Kingdom and Ireland. Fortunato and Clevenger (2017) investigated the progress of communities deeply rooted in a culture based on entrepreneurship and leadership development. Despite increasing attention paid to community progress and entrepreneurship, this matter is still under-investigated in the tourism field. However, it is worth noting several case studies on community tourism (Heesup, Taeyeon, Amr, Taeyeon \& Wansoo, 2019; Manhas, Gupta \& Gupta, 2014, Janjua et al, 2021). In this respect, we mention three major characteristics within the studies above, most of them carried out in developing countries or targeting developing countries. Hence, poverty reduction was the purpose of rural community tourism progress. To this end, community participation has been one of the favourite topics. Secondly, out of the three factors (environmental, social and economic), in the sustainability field, environmental and social factors have represented a focus point. Some studies have even approached the two aspects jointly. Thirdly, methodological/qualitative approaches have constituted the most common types of investigations. There is not just one method of development but it is their combination that generates positive effects on the territory and on the communities that populate it (Ivona, 2021). 


\section{Enhancing multifunctionality}

The issue with enhancement through market mechanism is that multifunctionality markets have not been fully determined, which means that both customers and producers often fail to recognise the relevance of the multifunctionality effects. Under these circumstances, it is hard to enhance them suddenly; hence, we should consider a staged approach to enhancement (Ohe, 2011). Such a gradual enhancement is an innovative process, hence the name "gradual innovation". Producers may enhance the effects as the diversification of agrarian activity progresses through the management efforts of entrepreneurs. Thus, as farm diversification advances, tourism operators have more possibilities of enhancing effects. It is often said that rural tourism is a relative example of the success of recreational components within the enhancement process (OECD, 2005). The effects of multifunctionality concern a new agrarian business by forming a new role for agriculture in society. In the initial phase, most customers and producers fail to observe the value of the positive effects generated by producers, despite producers being aware of the positive effects per se. Naturally, the demand level is still low in this phase, while producers reach their optimum level only from a private and not from a social point of view. If the positive effect does not exist, the private optimum point is also the socially optimum point. However, this is not the case when positive effects occur. In this phase, the effect is not valorised, which means that society receives benefits without paying producers any price (Ohe, 2011). For instance, if producers fail to acknowledge the actual value of the effect, they conduct their activity in the private optimum point. It is reasonable behaviour for producers when the price of the positive effect is not paid. However, if producers do not increase the income, there is no perspective for developing a new rural business in the long run. Hence, something should be done to enhance the positive effects, to determine a new and economically viable activity.

The next step is enhancement per se, but rural tourism studies show that it is both impossible and impractical to pass directly from zero to perfect enhancement. In the following phase, producers realise the importance of enhancing the positive effects, and they try to get back the average price (i.e., the material costs); hence, at that point, they receive the average price. However, a part of the positive effect is still uncovered. Some producers conduct their activity at this level. For instance, in this case, producers assume they run leisure activities not because they seek profit but because they want to cover the material costs and avoid losses. (Ohe, 2007).

Such behaviours depend on the producers' attitudes on how they place positive effects within their agrarian business. Namely, if they see positive effects as a new income opportunity or as volunteering services for the community. It is, of course, a matter of personal choice. At a business level, rural tourism activity is still not viable. Therefore, it is necessary to advance to a new level. The network must be extended through exchanges between producers and customers to get to the next level because the extension of this network helps producers obtain several opportunities to develop new ideas for better enhancing measures. It is due to rural tourism being an intangible product, unlike traditional food production leading to tangible goods, which may be stored for a certain period. The service has a production and consumption simultaneity, which means that customers must be 
present physically when production takes place (Niță \& Butnaru, 2005). There are two types of simultaneity: temporal and spatial. Temporal simultaneity means that it is not possible to store services and, as such, inventory may not be adjusted by supply. Spatial simultaneity indicates that it is not possible to ship services and, as such, shipping cannot be adjusted by supply.

In the case of rural tourism, if customers wish to enjoy the experiences of harvesting grapes, they should come and visit the location in the summer or autumn, when the grape harvest takes place. Otherwise, they miss their chance. Hence, locality and agrarian heritage provide simultaneity to rural tourism, adding diversity and differentiating it from other services. These features suggest two advantages. Firstly, the rural tourism market may be segmented temporally and spatially, creating an opportunity to develop a local culture-based rural tourism activity (Ohe \& Ciani, 2011). The tangible and intangible factors related to rural heritage (i.e., local cuisine, traditional architecture, agrarian lifestyle and warm rustic hospitality) could be considered ingredients of culture-based rural tourism activity. Thus, rural tourism allows producers to mobilise, on a larger scale, the local resources redeemed in the case of mono-farm production activity and to use and conserve their rural heritage. If producers reach this point, price elasticity lowers, which means that producers may take price initiatives, thus feeling less pressure to change the shipping costs. Another advantage of simultaneity is that the exchange and feedback between producers and customers occur easily during services provision. The meaning of feedback is essential for rural tourism businesses because the feedback of customers shows their satisfaction and complaints. From feedback, producers learn the potential needs of customers and how to improve the quality of services. They also learn to trust their capacity as producers and see their local community as a reliable destination for tourists. In this respect, feedback and exchange are necessary conditions for innovations in rural tourism (Ohe, 2007).

On the other hand, simultaneity also has downsides because non-storability and non-shipping generate a significant gap between peak and off-season demand, which is known as an issue of demand seasonality. Seasonality inevitably causes income fluctuations due to the inefficient use of resources (entailed by mid-season congestion and off-season underuse). This fluctuation is further accelerated by the meteorological conditions, given that rural tourism targets tourists outside the rural areas. For these reasons, fluctuations should be reduced to a minimum for effective use of agricultural resources and stable activity of agricultural enterprises. It means that service management is crucial for successful rural tourism from various perspectives (Lovelock \& Wirtz, 2016). If producers run a viable business, the enhancement of the positive effects of multifunctionality is a success. The change depends on the management capacity of producers. Therefore, software aspects (i.e., management of services) are more relevant for innovation than hardware aspects in the mobilisation of rural and agricultural resources concerning rural tourism activity. The intriguing characteristic of rural tourism is that multifunctionality improves through rural tourism, which creates a new social value continuously, though it is not viable initially. Rural tourism may create an opportunity for a new service and product within this social value. In this respect, one should not underestimate the relevance of multifunctionality. Ohe proves in his research the empirical evidence for the positive recursive relationship between multifunctionality and rural tourism. He concludes that community work generates 
and improves multifunctionality, while positive effects may be enhanced by a community relying on rural tourism than by an individual agricultural producer.

Considering the enhancement of agriculture multifunctionality positive effects, if the enhancement of positive effects is complete, we examine the characteristics of rural tourism. In a traditional rural economy, agricultural products are generally shipped from rural areas to urban markets (and consumed there). A typical example of this assumption is "The Isolated State" of von Thunen (Clark, 1973). In this case, the market of agricultural products (i.e., food) is located exclusively in the urban area. Of course, the residents within the rural areas go to local agrarian shops to buy food, and this behaviour is considered a traditional food buying category. On the other hand, rural areas attracted urban inhabitants to buy local products from the agrarian shops and enjoy rural tourism. People visiting the rural areas buy fresh agricultural products and enjoy quality leisure time. It indicates that the purchase behaviour displayed by urban residents shifts from urban to rural areas, besides the traditional agricultural product flow from the rural to the urban areas. This trend is considered an outcome of the developing rural market.

There are two markets, separated spatially: urban market and rural market. Though it means that prices are specific to each market, there is a difference if prices are based on the manufacturing location. Hence, we assume a different location for each and a difference between production and consumption place. Secondly, shipping costs must be considered (due to the different markets locations and the distinct production and consumption places). Producers must deliver the agricultural products to the urban market; also, urban residents must visit the rural areas to enjoy rural tourism. The tourists may include the shipping in the cost of a tour to the rural area (i.e., the shipping cost is not additional). Thus, the travel expenses are deductible, given the positive utility. In other words, if travel to the rural area is seen as a form of rural tourism for which urban residents are willing to pay transportation fees, this is one of the conditions justifying the creation of rural markets for urban residents.

Third of all, the contents of shipping fees comprise the following: (a) the direct shipping of agricultural products and processed foods; (b) in the case of travel, the public transportation cost or the cost of car fuel, including a driving opportunity cost and (c) the psychological transportation cost. The last depends on the preference for the rural area, different from one customer to another, and the attractiveness of the destinations. Therefore, the psychological cost for a customer who prefers rural areas is lower than for a consumer with a lower propensity for them. Fourth of all, it is assumed that the implicit cost in food purchase by residents on each market (i.e., the urban market for urban residents and the rural market for rural inhabitants) is zero.

Fifthly, the rural market comprises local and urban residents, too. Because the purchase behaviour of residents on rural markets is dominated by daily consumption behaviour, it is essential to develop rural markets. Hence, the number of visitors from the densely populated urban areas adds to the residents.

There are differences between the goods purchased while travelling to a rural area and the traditional agricultural products bought from an urban market. Goods available on an urban market are regular agricultural products within rural areas. These products are generally shipped through the mass distribution systems of agricultural cooperatives, retailers and distributors to urban markets (displaying high demand and providing consumption). In this respect, it is a mass market. 
Usually, the cost of products includes shipping, and it influences price increases. On the other hand, in the rural markets where tourism flourishes, urban residents are the dominant components of demand. Specifically, rural tourism products are services included in farm accommodation, meal services in farm restaurants, agricultural and rural experiences and farm visits for leisure purposes. The direct sale of agricultural products and processed goods are also included in the category of rural tourism products because customers normally cover shipping costs at the purchase point. Products listed as services (as we mentioned before) have a production and consumption simultaneity. Essentially, customers pay for shipping to get to the destination because they cannot enjoy the services unless they visit the production site, when and where such services are available. Whatever the shipping/transportation fee chosen by customers, they pay the actual travel cost, including the one for visit opportunity. The size of markets for rural tourism goods is significantly smaller than the mass market for traditional agricultural products. Hence, the market of rural tourism services is considered a niche market, as the literature often highlights. It is assumed that these characteristics lead to higher elasticity of demand concerning regular agricultural products such as food. In the context of multifunctionality, while rural tourism may provide income by using the advantages generated by multifunctionality, regular agricultural products are considered neutral for the use of multifunctionality by cashing in income from agricultural production. These markets are not thought to replace producers but represent an addition. When considering the two possible markets, it is easier to extend perspectives towards farm diversification.

\section{Conclusions}

The features of rural tourism entail two advantages. Firstly, the rural tourism market may be segmented temporally and spatially. This division creates an opportunity to develop a culture-based local tourism activity in rural areas. Tangible and intangible factors related to rural heritage (i.e., local food, traditional architecture, agrarian lifestyle, rustic hospitality) represent ingredients of culture-based rural tourism. Hence, rural tourism allows producers to mobilise on a broader scale the local resources previously unused in the case of mono-farm production activity. It provides the chance to use and preserve their rural heritage. Another advantage is that simultaneity allows exchange and feedback between producers and customers through service provision. The meaning of feedback is essential for rural tourism businesses because customers' feedback shows the satisfaction and dissatisfaction points accurately. From feedback, producers may learn potential customers' needs and ways to improve the quality of services. Feedback also allows them to trust their capability as producers and the rural community they grew up in as a reliable destination for tourists.

If producers can manage the business efficiently, the enhancement of the positive effects of multifunctionality would be a success. This change depends on the producers' management capacity. Hence, the software aspects (i.e., service management) are more relevant for innovation than hardware aspects in the mobilisation of rural and agrarian resources for rural tourism activity. The intriguing characteristic of rural tourism is that multifunctionality improves through rural tourism. Thus, it creates a new social value permanently (though the social value may not be viable initially). Rural tourism may create an opportunity for a new 
service and product from the social value. In this respect, one should not underestimate the relevance of multifunctionality.

Rural tourism allows producers to mobilise, on a wider scale, the local resources redeemed in the case of mono-farm production and get the chance of using and conserving their rural heritage. If producers attain this goal, price elasticity lowers, which means that producers may take price initiatives, thus mitigating the pressure on changing shipping costs.

\section{References:}

1. Clark, C. (1973). The value of agricultural land. Oxford: Pergamon Press.

2. Epuran, G.; Tescas,iu, B.;Tecău, A.-S.; Ivasciuc, I.S.; Candrea, A.N. (2021) Permaculture and Downshifting-Sources of SustainableTourism Development in Rural Areas, Sustainability, 13(230), pp. 1-19.

3. Fink, M., Loidl, S., \& Lang, R. (2013). Community-based entrepreneurship and rural development: creating favourable conditions for small businesses in Central Europe. Abingdon: Routledge.

4. Fortunato, M., \& Clevenger, M. (2017). Toward entrepreneurial community development: leaping cultural and leadership boundaries. New York: Routledge.

5. Haughton, G. (2013). Community economic development. London: Routlege.

6. Heesup, H., Taeyeon, E., Amr, A.-A., Taeyeon, B., \& Wansoo, K. (2019). Community-Based Tourism as a Sustainable Direction in Destination Development: An Empirical Examination of Visitor Behaviors. Sustainability, 11(2864), pp. 1-14.

7. Ivona A., (2021). Sustainability of Rural Tourism and Promotion of Local Development, Sustainability, 13(6), DOI: 10.3390/su13168854, pp. 1-7.

8. Janjua, ZU., Krishnapillai, G., \& Rahman, M. (2021). A Systematic Literature Review of Rural Homestays and Sustainability in Tourism. Sage Open, 11(2), DOI 10.1177/21582440211007117, pp. 1-17.

9. Knollenberg, W., Brune, S., Harrison, J., \& Savage, A. (2021). Identifying a community capital investment portfolio to sustain a tourism workforce. Journal of Sustainable Tourism, pp. 1-17.

10. Lovelock, C., \& Wirtz, J. (2016). Service marketing: people, technology, strategy, 7th Global edn. Singapore: Pearson.

11. Manhas, P., Gupta, D., \& Gupta, A. (2014). Strategic development policies and impact studies of sustainable rural and community-based tourism. Delhi: Primus Books.

12. Niță, V., \& Butnaru, G. (2005). Gestiune hotelieră - curs, aplicații, grile. Iași: Editura Tehnopress.

13. OECD. (2005). Annual Report, [Online], Available: https://www.oecd.org/about/34711139.pdf [01 Nov 2021]

14. Ohe, Y. (2007). Multifunctionality and rural tourism: a perspective on farm diversification, Journal of International Farm Management, 4(1), pp. 1-23.

15. Ohe, Y. (2011). Evaluating internalization of multifunctionality by farm diversification: Evidence from educational dairy farms in Japan. Journal of Environmental Management, 92(3), pp. 886-891.

16. Ohe, Y., \& Ciani, A. (2011). Evaluation of Agritourism Activity in Italy: Facility Based or Local Culture Based? Tourism Economics, 17(3), pp. 581-601.

17. Robinson, J., \& Green, G. (2011). Introduction to community development: theory, practice, and service-learning. Thousand Oaks: Sage Publications. 
18. Walzer, N. (2009). Entrepreneurship and local economic development. Lanham: Lexington Books.

19. Zahra , A., \& McGehee, N. (2013). Volunteer Tourism: A Host Community Capital Perspective. Annals of Tourism Research, 42, 22-45. 